\title{
Low-dose radiotherapy for SARS-CoV-2 pneumonia
}

\author{
Deep Chakrabarti ${ }^{1}$ (D) $\cdot$ Mranalini Verma $^{1}$
}

Received: 16 April 2020 / Accepted: 5 May 2020 / Published online: 11 May 2020

(c) Springer-Verlag GmbH Germany, part of Springer Nature 2020

The novel coronavirus (SARS-CoV-2) which emerged in the province of Hubei, China in December 2019 has already accounted for more than two million cases worldwide. In general, it is an acutely resolved viral respiratory illness that presents with high-grade fever, cough and dyspnoea, with bilateral pneumonia on imaging $[1,2]$. The plasma levels of cytokines like interleukins (IL2, IL7, IL10), platelet-derived growth factor (PDGF), vascular endothelial growth factor (VEGF), and tumour necrosis factor alpha (TNF $\alpha$ ) are usually elevated, with the levels being higher in patients who require intensive care or are categorised as having severe disease [1]. Nearly every sixth patient develops acute respiratory distress syndrome, which is predisposed by older age and known comorbid conditions, and which may worsen rapidly, leading to eventual death [2]. Management involves empirical and supportive therapy, but no standard of care has been established yet.

Historically, low doses of X-radiation were used in the first half of the twentieth century to treat pneumonia, including viral pneumonia, with subjective response and objective resolution [3] based on the ability of low-dose radiation to induce an anti-inflammatory phenotype [4]. Acute inflammation progresses in a cascade facilitated by inflammatory mediators, cell adhesion molecules, and interactions between endothelial cells and leucocytes. Low-dose radiotherapy decreases expression of molecules for cell adhesion, produces anti-inflammatory mediators like IL10 and transforming growth factor beta 1 (TGF- $\beta 1$ ), increases apoptosis, and secondarily reduces leucocyte-endothelial cell interaction and vasodilation by inhibiting the expression of inducible nitric oxide synthase (iNOS), which contributes to reduced nitric oxide levels [5-7]. Additionally, low-dose radiotherapy can contribute to hyper-radiosensitivity, further enhancing apoptotic death [8].

Mranalini Verma, M.D.

drmrinalini79@gmail.com

1 Department of Radiation Oncology, King George's Medical University, Lucknow, India
While most of our knowledge on the use of X-radiation to treat pneumonia comes from case reports and case series published more than half a century ago which do not count as robust evidence in the present day [3], the prospects seem promising under the current circumstances. A single fraction of low-dose radiotherapy is cost and time effective and could potentially alleviate symptoms of respiratory distress quickly, helping to reduce mortality without significant long-term sequelae. This, in turn, facilitates early discharge from hospital and reduces costs of in-patient hospitalisation, ultimately leading to better resource utilisation in the face of a global emergency. The strategy merits international cooperation and rapid evaluation in a randomised controlled trial. For a pandemic that originated in Hubei, one can look to the Chinese philosopher Confucius for words of wisdom: "Study the past if you would define the future". The past may indeed hold the key.

Conflict of interest D. Chakrabarti and M. Verma declare that they have no competing interests.

\section{References}

1. Huang C, Wang Y, Li X, Ren L, Zhao J, Hu Y et al (2020) Clinical features of patients infected with 2019 novel coronavirus in Wuhan , China. Lancet 395:497-506. https://doi.org/10.1016/ S0140-6736(20)30183-5

2. Chen N, Zhou M, Dong X, Qu J, Gong F, Han Y et al (2020) Epidemiological and clinical characteristics of 99 cases of 2019 novel coronavirus pneumonia in Wuhan, China: a descriptive study. Lancet 395:507-513. https://doi.org/10.1016/S0140-6736(20)302117

3. Calabrese EJ, Dhawan G (2013) How radiotherapy was historically used to treat pneumonia: could it be useful today? Yale J Biol Med 86:555-570

4. Calabrese EJ, Dhawan G, Kapoor R, Kozumbo WJ (2019) Radiotherapy treatment of human inflammatory diseases and conditions: optimal dose. Hum Exp Toxicol 38:888-898. https://doi.org/10. 1177/0960327119846925

5. Reichl B, Block A, Schafer U, Bert C, Muller R, Jung H et al (2015) DEGRO practical guidelines for radiotherapy of non-malignant disorders: Part I: physical principles, radiobiological mechanisms, and radiogenic risk. Strahlenther Onkol 191:701-709. https://doi.org/ 10.1007/s00066-015-0865-8 
6. Royo LT, Redondo GA, Pianetta MÁ, Prat MA (2020) Low-dose radiation therapy for benign pathologies. Rep Pract Oncol Radiother 25:250-254. https://doi.org/10.1016/j.rpor.2020.02.004

7. Roedel F, Kley N, Beuscher HU, Hildebrandt G, Keilholz L, Kern P et al (2002) Anti-inflammatory effect of low-dose X-irradiation and the involvement of a TGF-beta1-induced down-regulation of leukocyte/endothelial cell adhesion. Int J Radiat Biol 78:711-719. https://doi.org/10.1080/09553000210137671

8. Marples B, Collis SJ (2008) Low-dose hyper-radiosensitivity: past, present, and future. Int J Radiat Oncol Biol Phys 70:1310-1318. https://doi.org/10.1016/j.ijrobp.2007.11.071 